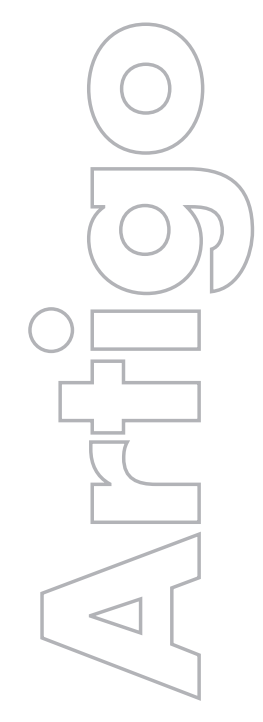

revista

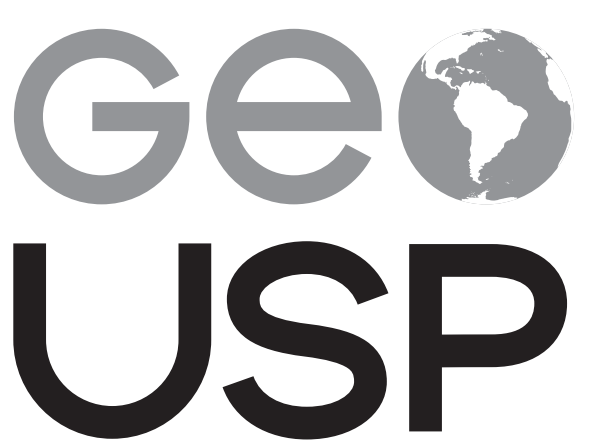

espaço e tempo

Volume $23 \cdot n^{\circ} 1$ (2019)
A paisagem e o geográfico do espaço: o onde da ontologia em geografia

\section{Bernard Teixeira Coutinho}

UERJ

e-mail: plumuarte@hotmail.com

p. $009-021$

Como citar este artigo:

COUTINHO, B T. A paisagem e o geográfico do espaço: o onde da ontologia em geografia. Geousp - Espaço e Tempo (Online), v. 23, n. 1, p. 009-021, abr. 2019. ISSN 2179-0892.

Disponível em: https://www.revistas.usp.br/geousp/article/ view/96818. doi: https://doi.org/10.11606/issn.2179-0892. geousp.2019.96818.

\section{(c) (i) (2)}

Este artigo está licenciado sob a Creative Commons Attribution 4.0 License. 


\title{
A paisagem e o geográfico do espaço: o onde da ontologia em geografia
}

\section{Resumo}

A percepção parece ser o termo mais ligado ao conceito de paisagem, o mais difundido, estudado e, concomitantemente, o mais confuso. Ao mesmo tempo em que dá ao conceito condições de esclarecimento, difunde questões variadas como aquelas de natureza metódica e metodológica. Aqui, nosso esforço é pensar a percepção sobre a paisagem por uma orientação ontológica, de modo a estabelecer relações com a prática da abstratividade do trabalho intelectual e com o geográfico do espaço.

Palavras-chave: Paisagem. Geográfico. Abstração. Ontologia. Epistemologia.

\section{The landscape and the geographical space: the where of the ontology in geography}

\begin{abstract}
The perception seem stobe more related to the concept term landscape, the most widespread, studiedand, concurrently, the more confused. At thesame time as it transfers the concept clarification conditions, it diffuses variedissues as those of methodical nature and methodological. Our effort here is to think an awareness about landscape by an ontological orientation, so to get acquainted with the practice of abstract ness of intellectual work and the geographical of the space.
\end{abstract}

Keywords: Landscape. Geographic. Abstraction. Ontology. Epistemology.

\section{Introdução}

$\bigcirc$ presente artigo busca altercar as relações existentes entre o trabalho da intelecção e o modo como percebemos e representamos a organização da paisagem que, como conceito, se coloca como um desafio para a construção da ideia concreta. $\bigcirc$ texto foi organizado em tópicos que representam, em certo grau, a forma pela qual poderíamos conceber a estrutura da realidade da paisagem, levando em conta os fenômenos constituintes e o método de representação possível. 
A discussão não buscou alimentar um projeto de maturação de um conceito, nem desenvolver uma revisão bibliográfica sobre a paisagem. Pretendeu, na verdade, conduzir um discurso menos privativo (denominado "falação") e mais polissêmico, ao guiar-se por uma tentativa de fala apoiada na ontologia.

\section{Antes do conceito, o homem}

Há de se esperar do mundo um punhado de respostas pelas quais nós, seres mundanos, seríamos capazes de emitir sentenças e valorações acerca disso ou daquilo. $\bigcirc$ mundo é a orientação de conduta e, os seres mundanos, criadores da prótese desta condição. Cada vez que o condicionante - o construto paradigmático - estabelece relação com a moralidade humana, ambas anunciam a singularidade do homem e a universalidade do mundo. Ainda que epistemologicamente dissequemos o mundo que não é o "nosso", pomo-nos à disposição do que, verticalmente, se coloca acima de nós e saímos por aí afora experimentando um individualismo exacerbado. Então, a moralidade já não seria erguida pela Humanidade, mas habilmente experimentada por quem a concebe e dela participa.

Pela singularidade que agita as possibilidades mundanas do homem individualizado-individualizador, o mundo desvelado na abstração oferece ao pensamento antropocentrado recursos cognitivos, instrumentos de inserção ao universal, elementos genealógicos do saber-pensar filosoficamente e/ou cientificamente, mas também impõe limites. $\bigcirc$ mundo em-si se metaboliza no para-si. Antes como entidade universal, agora, como abstração universalizante. Nesse movimento incessante do real, o singular se reduz às poucas maneiras de aparecimento e continua mergulhado na abstratividade do homem-no-mundo.

mundo é signo e na forma mais simples da palavra: é algo que se abstrai e que, mediante a abstração, se apresenta como coisa ou objeto indutor. $\bigcirc$ mundo não sou "eu", nem os outros, mas uma arrumação seletiva e reflexiva do que se inscreve no real. Não sendo na impessoalidade, o mundo recorre aos meios de abertura pela associação. Como objeto, a partir da construção técnica - e aí, neste caso, construção teórico-reflexiva -, o mundo se engaja na relação com outrem pelo "para". E isso se arranja na e pela associação representacional no imediato.

\section{Entre o homem e o conceito, a abstratividade}

É pela representação que o homem se dirige ao mundo. Representar é a atividade intelectual e individual (sentido que faz referência ao indivíduo humano e não propriamente a sua singularidade ou, ainda, individualidade) pela qual a hominização do homem se fortifica e lhe sugere maior abertura ao que não se conhece. Por isso, representar é também revelar o que não se vê. Por este processo, o homem individual se consubstancia no outro porque direciona a sua reflexão ao mundo. Sendo esse um signo, é o pensamento a relação do "eu" com o não eu, aprioristicamente, que se configura como o eu que eu mesmo sou. Daí a indução pelo objeto soar lições de maturidade reflexiva e apontar horizontes da existência que delimita um lugar, ora improvisando uma tensão por antagonismo, ora descortinando uma relação dual. 
A associação distribui, assim, condições indiciais ou de significância, mas também de semelhança. Por isso que, pela abstratividade, as fronteiras do em-si não são totalmente rompidas, já que o próprio mundo objetivado conserva em seu interior a imediaticidade da estética presentificada. De um lado, é um mundo preservando, ele mesmo, as suas formas pela analítica dos seres mundanos; de outro, um mundo regido que aponta as possibilidades que "dá a entender" ser isso ou aquilo uma feição do real. Ambos os "mundos" formatando ideias que não se projetam solitariamente, mas dirigidas a alguém, por isso, na atividade pragmática.

Pelas condições indiciais, é possível verificar que, diante do objeto, há algo que insinua o que ainda não se vê. $\bigcirc$ ato de experimentação sugere uma inexperiência influenciada não pela intuição, mas mediante a previsibilidade que se encontra nesse próprio objeto. Quando olhamos os objetos e as coisas que estão distribuídas no mundo - arrumação que se convencionou chamar "paisagem" -, imediatamente apontamos direções interpretativas e, por elas, formatamos opiniões acerca de sua forma. Nesse caso, o que convoca a ação de percebimento é a indução, o que a forma abriga em seu bojo. É a funcionalidade ou a característica do objeto, que entendemos por qualidade.

Quando, a título de exemplo, diante de um relógio solar, medimos a passagem do tempo, a instrumentalidade do objeto insinua uma operacionalização, um manuseio para dada finalidade que, neste caso, é a medição da duração dos dias. No ato de utilização do objeto, se sabe que, em determinado momento, o tempo irá "passar". Isso é previsível, mas codificado pelo instrumento técnico e pela instrumentalidade. A construção e a utilização deste objeto independem das filosofias de Bergson, Aristóteles, Santo Agostinho, do relógio moderno etc. Nesse sentido, a inexperiência de que falamos não traduz a falta de contato com o depois, porque ele pode vir a se repetir, mas é o ainda-não da experiência e também do objeto. $\bigcirc$ agora é o dia e, o depois, a noite. $\bigcirc$ anoitecer é a previsibilidade, e a passagem do dia para a noite é desvendado pelo relógio, daí o olhar se voltar para a duração do tempo.

Por meio das condições de semelhança, o objeto nos reporta a algo que nele é representado. Não é um caso metalinguístico, porque não se refere ao aparecimento do mesmo, mas do outro semelhante. Exemplo: uma imagem da paisagem. A apreensão imagética pode, pela similitude, dispensar o próprio objeto. Se for representado pela fotografia ou por uma escultura, a paisagem aparece, mas não desaparece quando o objeto se ausenta da análise. Isso porque o que interessa, neste caso, são as qualidades do objeto, e não necessariamente o próprio objeto. Fala-se, aqui, do significado.

Diferente disso, o símbolo é o significante. E é por onde o pensamento abstrai o objeto pela representação. Representa-se um objeto sem qualidades e/ou um objeto com qualidades que se orienta pelas possibilidades dadas pela oposição ou pela complementaridade. $\bigcirc$ símbolo é o mundo representado, a vida, a morte, o espaço, a paisagem, os seres mundanos.

1 Termo da filosofia fenomenológica de Heidegger, o ainda-não relaciona-se com o modo com que ontologicamente a presença existe. Diz o filósofo que "a presença sempre existe no modo em que o seu ainda-não lhe pertence" (Heidegger, 2009, p. 317). O ainda-não se mantém provisoriamente. Ele ainda está contido na presença, ainda que se mostre no plano do "não real". O fato é que o "ainda não" não pertence ao exterior, porque já faz parte do próprio ser. Heidegger (2009, p. 318) ainda expõe que "enquanto algo à mão, a soma incompleta é indiferente' ao resto que falta e não está à mão. Em sentido rigoroso, a soma não pode ser nem indiferente nem não diferente". A presença, como tal, já é o aindanão. 


\section{A falação como instrumento constitutivo do discurso do homem}

No pragmatismo, o caminho do movimento das histórias individual-coletivas situa-se numa relação zonal-reticular, por onde os percursos anunciam a copertinência entre o homem e o princípio de toda e qualquer falação: o geográfico. Antes do discurso, há o sentido de localização, de sítio, daí a relação que o homem estabelece no geográfico ser uma (com)posição. ${ }^{2}$ Quando não é isso, a dualidade se estabelece, reificando a interação e dirimindo as possibilidades de uma representação humana. É por essa razão que o geográfico "é" a medida de uma associação representacional no imediato. $\bigcirc$ mediato é o instante posterior da abstração, lócus que disponibiliza o composto, o disposto e o oposto. Estas três definições "estão", e é aqui que nascem os discursos dos seres mundanos. Isso porque o discurso (des)cobre as barreiras do interior e é externalizado na e pela falação. Do início ao final do processo o geográfico está presente; o geográfico é, fundamentalmente, espacial.

Na falação, a relação orgânico-inorgânico apresenta uma primeira duplicidade. Enquanto o orgânico diz respeito à presença do homem-no-mundo, o inorgânico é o onde dessa manifestação ontológica. Seja o cogito de Descartes, quando pensado no em-si, ou o meio, quando se privilegia a relação, o inorgânico é sempre uma condição vital ao orgânico. A dicotomia advém do discurso, não da relação estabelecida entre os pares. Não que sejam dadas pela natureza, mas que, pela relação com o próprio inorgânico, o homem se cerca de possibilidades dadas entre os pares. A dicotomia é a oposição na relação homem-meio.

\section{"Geografema": do léxico ao objeto e do objeto ao discurso}

As duplicidades, então, orientam uma universalidade embutida no próprio mundo, na própria constituição dos seres mundanos pensantes deste mundo; um mundo que organiza o pensamento e que, por ele, apresenta nuances diferenciadas. Volta-se ao "eu" antes do objeto, mas parte-se da fala para referir-se a este último. Tem-se, a partir disso, o significado e a quem o discurso se dirige. A partida não se dá na operacionalização raciocinada ou, mais simplesmente, numa lógica sistematizada cientificamente. $\bigcirc$ início é a própria universalidade, quando esta é entendida como um projeto modelar da constituição da forma, do signo-símbolo. Então, é ao significante que nos reportamos.

Enquanto isso, o significado forma e transforma o que se constitui, e não se remete à forma que já fora apreendida pela essencialização do em-si. $\bigcirc$ significado é atributo do movimento do pensamento que, atrelado a uma referencialidade, apresenta o conteúdo daquilo que se pensa. Poder-se-ia, por conseguinte, abarcar a essência. $\bigcirc$ significado induz, o significante é a singularidade que se projeta como qualidade na possibilidade de relação. "O que isso significa?" é uma questão exemplificadora deste caso, pois, ao passo em que a direcionamos para este ou aquele ente, ${ }^{3}$ nos acusamos a uma estética no em-si.

2 Sentido de localização em sua profunda relação com a distribuição é o fundamento da ontologia do espaço, sendo o uso posicional da superfície terrestre garantidora desse processo, além de ser uma das categorias da categoria "espaço" juntando-se a outras como, por exemplo, localização, distribuição, extensão, distância e escala (Moreira, 2010).

3 De acordo com Heidegger (2009, p. 42), "ente é tudo de que falamos dessa ou daquela maneira, ente é também o que e como nós mesmos somos". 
De modo mais adequado, é o significante que, no em-si, abriga o objeto apartado de adjetivações, como se dele não fosse necessário retirar os elementos que movem a relação. Advém dessa concepção a ideia de paisagem como conceito inerte ou objeto à margem da totalidade, uma paisagem que seduz o olhar e o deturpa na aparência, porque se manifesta como fenômeno. A essência é desvinculada da aparência. Quando o olhar é científico, a paisagem torna-se objeto e, como tal, se distancia das suas qualidades, que é por onde a essência do geográfico supostamente se estabelece. Daí a pergunta "o que isso significa?" admitir diversas respostas.

Quando nos reportamos ao em-si da paisagem, os elementos do duo homem-meio não se relacionam e, a rigor, não demandam esse movimento, porque a relação é a inserção à qualidade do objeto. É "natural" pensar o signo como um fenômeno e este como a face ilusória do real, quando não estabelece relação com a materialidade. Mas a naturalização é um processo que se anima pelo construto linguístico (leia-se: epistemologia) no significante. Cria-se, assim, um modo universal de ver o mundo. E são criticados, no significante, os pares que surgem, nessas condições, por dicotomia. Homem-meio pode ser uma dicotomia ou uma relação; homem-mundo, também. Poder-ser indica possibilidade de um objeto que, distanciado de suas qualidades, não inaugura a relação, mas é ente porque passível de se fazer relação. Por isso, o geográfico deixa de fazer parte das dimensões da realidade.

\section{Intuição como (re)velação do ser do objeto em-si}

$\bigcirc$ modo como a relação se estabelece entre os pares, que aqui estão grafados em homem-meio, admite uma postura do pensamento diante da arrumação dele mesmo frente à realidade. O real, a partir daí, é mediado por uma duplicidade outra, a saber: imediato-mediato. Esta articulação ou se apresenta na oposição ou na "cumplicidade", que ocasionalmente preferimos denominar copertinência. $\bigcirc$ problema não é mais identificar o pensamento no imediato ou no mediato, mas encontrá-lo na articulação, isso porque ela é múltipla. Conforme já se falou, no em-si a abstratividade se volta ao objeto e, a partir dele, constrói um raciocínio teórico. Quando feito neste campo, a qualidade do objeto não é levada em conta, e fala-se aqui da referencialidade espaço-temporal e de todos os seus elementos (função, forma, conteúdo, processo), e não apenas da sua estrutura, outro elemento fundante do objeto.

Esta modulação ocorre porque o sentido de olhar o mundo e de concebê-lo pela lógica encaminha-nos sempre a uma duplicidade, dependente ou independente da relação; no em-si ou na alteridade entre os entes presentes no mundo. Quando manifesto no em-si, a estrutura identifica uma marca da intuição do homem que, pela singularidade, dirige-se ao que é intuído. Quando o fenômeno se abre no para-si, o significado e a referencialidade conformam a abstratividade, a partir da conformação epistemológica da ciência. Centra-se o olhar teórico no objeto e em suas qualidades.

\section{O geográfico como decorrência da simbiose forma-conteúdo}

mundo é signo, o homem é signo. Mas o que difere o mundo do homem? Assim como mundo e homem são signos, ambos são entes. Tanto um quanto outro t6em forma, que é por onde a representação se permite atuar, e também conteúdo, por onde a apreensão capta os 
símbolos - signo linguístico, modelo estético - e os significados. $\bigcirc$ geográfico é a relação entre os pares que se estabelecem na associação representacional do imediato que, no mediato, organiza o pensamento orientando-o nas significações. Os pares são pressupostos do nosso modo de ver as coisas do mundo, mas não necessariamente as dicotomias.

No campo das significações, ou mesmo dos significados, o meio pressupõe a existência do homem e o homem pressupõe a existência do meio. Já no sistema sígnico, a dependência entre os pares inexiste. Quando se representa dado recorte espaço-temporal, o que se vê são os signos, não os significados. Na Geografia Regional Francesa, a paisagem era tida como aquilo que poderia ser apreendida pela representação cartográfica. $\bigcirc$ mapa representa determinados signos, particularmente aqueles objetivados na "paisagem". Como as significações não podem ser apreendidas pelas técnicas cartográficas, a paisagem se torna aquilo que pode representar no mapa, apreendido epistemologicamente e descrito. Daí o relativo sucesso das monografias regionais francesas da mesma época.

De lá para cá, o conceito recebeu inúmeras designações, mas continua sendo atravessado por um conservadorismo sustentado pela tradição do pensamento geográfico. A paisagem bem parece a porta de entrada de outros conceitos. Ela está assentada no modo estético-estático de olhar o mundo que, por essas circunstâncias, se estabelece de modo inatual. Diante disso, paisagem se confunde com o símbolo, ignorando-se os duetos presentes no real - homem-meio e representação-apreensão, por exemplo - e estabelecendo dicotomias, eliminando a possibilidade do meio ser e do homem ser-no-meio.

\section{Depois da determinação, a paisagem-memória}

É comum, no tempo presente, saldarmos as alternâncias explicativas deste mundo que sobrevivem pela crítica que fazem ao que se conserva há séculos (veja-se a crítica dos adeptos do pensamento ultra ou pós-moderno às metateorias). ${ }^{4} \bigcirc$ foco da problemática não está inteiramente assentado num discurso, numa época, numa tendência, numa ruptura epistemológica ou num paradigma. A reflexão exige sempre a totalidade. $\bigcirc$ que está fora dela se congela e o que está dentro se move. A paisagem se localiza onde?

Quando o foco da analítica reflexiva se volta para a ontologia, a primeira atividade é, usualmente, criticar a modernidade, como se ela fosse o ens creatum e os homens modernos entes secundários. Os filósofos moderno-iluministas apostaram na racionalidade, no uso da razão, se debruçaram nesta ou naquela tarefa e pensaram sob a perspectiva da modernidade. A modernidade existe na medida em que o homem a concebe, não o inverso. $\bigcirc$ pensamento passou a ser a própria condição vital da existência, não numa interpretação rígida da sentença descartiana - "Penso, logo existo" (Cogito ergo sum) -, mas numa reflexão sobre si mesma.

Mediante a lógica cartesiana, o pensamento descartiano estabelece uma perspectiva filosófica (uns preferem denominar "paradigma") - a modernidade - que fora desdobrada, em seguida, por Kant, e não se encerrou neste (Moreira, 2010). A partir disso, a apreensão do mundo pela racionalidade diminuiu as possibilidades da representação das significações. Importa muito mais os símbolos, o signo que é a maneira em que se estabelece no mundo, do

4 As metateorias, metanarrativas ou metalinguísticas são, como coloca Harvey (2011), amplas interpretações "totalizantes" e "sistêmicas" que já não explicam a totalidade das dimensões mundanas do real. 
que os pares da secundidade (Santaella, 1985). Isto é, o interesse dirige-se àquilo que pode ser apreendido pelo uso fiel da razão, pelas medições e experimentações. A intuição e/ou o instinto não são captados pela representação racional, por isso não são apreendidos. Daí podermos entender as grandiosas descrições da natureza ou da "paisagem" feitas pelos primeiros geógrafos modernos, pois é herança direta desta concepção moderna.

Intuir é voltar às coisas mesmas; a inteligibilidade do real é, pela lógica, a superação das coisas mesmas. Isso não quer dizer que a intuição não possa formatar uma ontologia. Ontologia refere-se ao ser, mas não necessariamente se dá, na tradição filosófica, numa relação entre pares, vide a intuição pensada por Bergson (Os Pensadores, 1989). A ontologia pela secundidade - isto é, pela relação pragmática entre os pares - desvela a diferença entre o ser e o ente. No em-si, o ser se confunde com o ente, daí a (com)posição transformar-se em oposição ou, melhor, em (dis)posição, privando as qualidades do ente (ou de um objeto qualquer, quando não se fala do homem) sob a mesmidade. ${ }^{5}$ Daí a funcionalidade restringir-se ao técnico, ao manuseio, e não mais significar uma qualidade, uma função que é qualidade na relação com a intencionalidade técnica do objeto.

Nesse sentido, caminha-se para uma representação esvaziada de conteúdo (convencionou-se chamá-lo de "simbólico"), porque pela imagem se diz: "o mundo é desta ou daquela maneira". $\bigcirc$ "é" empregado representa um conjunto de possibilidades. $\bigcirc$ "é" fora empregado porque se refere à relação existência-pensamento (lembremo-nos da sentença descartiana), então o que existe é aquilo que vejo, codifico e represento. $\bigcirc$ movimento imagem-codificação-imagem escamoteia a ação do homem presentificada na representação orgânica relativa ao inorgânico.

A cartografia trabalha com signo-símbolo, na medida em que o conteúdo se entifica. Nessa determinação, os duelos - sujeito-objeto, subjetivo-objetivo, indeterminação-determinação, imediato-mediato, homem-meio etc. - expressam um esvaziamento conceitual. Isso porque a reflexão se respalda na dicotomia, não na associação, por isso, a paisagem se torna objeto e, objetivamente, transmuta-se em conceito-suporte da ciência geográfica.

Paisagem tem sido sempre o ponto de partida e o de chegada, raramente é tida como mediação. É nisso que repousa a tradição do pensamento geográfico. E aí a dicotomia homem-meio é expressa numa outra, a que recolhe por distanciamento sociedade e natureza, em que a natureza é um ente distante que permite sua transformação ora pelo labor cotidiano, ora pela espoliação capitalista. Eis, a propósito, a porta de entrada do turismo nas cidades pela "estetização da forma urbana" (Barbosa, 2011). Olhamos a paisagem "bela" e a contemplamos, quando não, cartografamos. Não seria a paisagem, na Geografia, um conceito-espetáculo? A qualidade da paisagem já não é transmitida por uma referencialidade, mas pela qualidade em-si. Com isso, o "mundo externo" que se apresenta como outra dicotomia é independente do "interno", daí a paisagem aprimorar suas qualidades em-si e se afastar do que se move, da totalidade. Por isso, ela é memória.

5 Ainda que vistos como uma não unidade, por se apresentarem de modo distinto, o mesmo diz respeito ao pensar e ao ser, bem como anunciara Parmênides, segundo Heidegger (Os Pensadores, 1973). Essa mesmidade, fazendo referência ao conjunto-unidade, pode ser ajuizada como sendo as diferenças entrelaçadas num só corpo, seja na ótica da unidade ou nos limites do mesmo. Eis o princípio de identidade: a mesmidade deturpa as fronteiras das diferenças e cria uma unidade que reclama por igualdade e configura a identidade. 
Em nossa concepção, a paisagem fornece o sentido de localização às formas geográficas e às relações entre os homens e as coisas-do-mundo. Ocupando-se da paisagem, o homem percebe a espacialidade, mas não sob a forma aparente e "primitiva" da abstração, como em Silva (2000). A paisagem não é uma primeira representação do espaço, por isso, o homem apreende, na paisagem, a espacialidade como uma totalidade do espaço. Diferentemente disso, a paisagem também tem sido compreendida como uma "aparência fenomênica" (Santos, 1988; Silva, 2000). Costumeiramente, a paisagem é definida ou como um momento do espaço em movimento para elucidar a totalidade do homem na paisagem (Dardel, 2011) ou para chamar a atenção para a totalidade da forma espacial. Elucidemos melhor isso.

De acordo com Dardel, a existência é movimento, porque é presença "atarefada", ou seja, inserida no movimento da Terra (o lugar), do espaço e da própria sociedade. Como ser social, o homem identifica sua própria velocidade e aquela bastante característica da técnica dos instrumentos, os da manualidade presente na paisagem. Assim, na ocupação, o homem-no-mundo apreende sua essência e a do espaço, porque é pelos objetos espaciais que o fluxo da vida vai sendo decodificado, incorporado. Nesse sentido, a paisagem não é nem o ponto de partida, nem o de chegada, mas o ponto de encontro do homem com a totalização, que é o espaço. Essa consciência geográfica (Dardel, 2011) do homem-no-mundo na paisagem é prolongada pelas múltiplas combinações de interesses entre o eu e o outro, pelo uso daquilo que Heidegger (2009) denomina utensílio, isto é, instrumentalizando as intencionalidades no mundo, a partir da percepção da funcionalidade de cada ente disposto.

Santos, por sua vez, atribui o caráter de totalidade ao conceito paisagem, quando se resgata o "trabalho sintético" de Sartre, aquele cujo objetivo é reunir as multiplicidades de uma dada totalidade (Bernardes, 2012). A paisagem (totalidade) é um momento do espaço geográfico (totalização) e, por ser isso, configura-se como um conjunto de objetos que se fixam no real. Portanto, são objetos reais, e não "formas aparentes", como quer Silva (2000), mas somente quando se ultrapassa a ideia de paisagem como "aspecto" e se chega ao seu "significado", porque cada homem-no-mundo enxerga a realidade "de forma diferenciada; dessa forma, a visão pelo homem das coisas materiais é sempre deformada" (Santos, 1988, p. 61), se considerarmos a paisagem como uma "coisa" só. Por ser um momento do espaço geográfico, "a paisagem é história congelada" (Santos, 2006, p. 69). De acordo com Santos (2006), existe um movimento de totalização porque se comporta como um recorte espacial apropriado para abrigar o tempo espacial.

Sé entre essas duas concepções diferentes sobre a paisagem é possível perceber duas divergências. A primeira diz respeito às considerações acerca da qualidade da paisagem como espacialidade da geograficidade. Para Santos, as ações humanas se estendem no espaço geográfico, não na paisagem, daí o autor privilegiar a forma. Mas, em Dardel, o ser social se põe como tal na paisagem que, para o mesmo, não se projeta apenas no "algo" material, mas também no imaterial. Daí, a paisagem ser muito mais do que uma área, pois ultrapassa as disposições materiais e artificiais. A cultura é impulso da geograficidade original, como dissera Dardel (2011), na e pela paisagem ou na paisagem cultural de Santos (1988). 
A segunda divergência recai sobre a percepção da paisagem. Para Santos, o seu limite é o visível, e isso já é um problema, porque se desenvolve na percepção. Para o autor, a percepção é a capacidade de selecionar o que se apreende, e isso cria uma multiplicidade de interpretações que a ciência geográfica poderia sistematizar pelo conhecimento. Desse modo, o verdadeiro não pode ser abarcado pela percepção, porque capta a forma aparente. Como bem coloca Bernardes (2012, p. 110), "o espaço geográfico, pelo contrário, é a paisagem pensada; é a abstração em outro nível, porque concreto". E, embora a forma se dê no espaço geográfico, há sempre um processo incessante em sua estrutura, mediado pelo movimento da totalização e pela funcionalidade, ou, função empreendida no real. Eis a essência do espaço em Santos. Por isso, a técnica no espaço geográfico possibilita um movimento constante de ações e de transformações dos objetos, o que na paisagem não se realizaria, porque ela é resultado, ou seja, arcabouço dos tempos pretéritos, do tempo espacial, e não dos eventos (Santos, 2006). É dessa maneira, a nosso ver, que a paisagem se estabelece como a memória das relações socioespaciais.

\section{Da contemplação ao fundamento ontológico de mediação da paisagem}

A paisagem é o horizonte, o ponto de encontro entre o homem afetável e o espaço cambiante, ambos dis-postos e/ou abertos às trocas pelo movimento guiado a partir do próprio curso das histórias dos homens no espaço geográfico. Dito de outro modo, é tanto o ponto de partida quanto o ponto de chegada da representação. Dirá Moreira (2010, p. 109):

Ver e pensar é, então, como podemos resumir o processo do método em geogra-

fia. Método que consiste em passar da descrição do visível da paisagem (o plano do sensível na geografia) à compreensão da estrutura invisível do espaço (o plano do inteligível), o que só vem com a intervenção estruturadora do conceito.

movimento que aparece pelo trajeto visível-invisível depende também do inverso invisível-visível, daí a paisagem estar no interior do real e não na indeterminação do sujeito, nem na determinação ordenada pelo conceito. A epistemologia, com isso, recodifica a paisagem e a torna uma concretude, mas também um "algo" concreto, porque pensado. Clarifica-se, assim, a presença tanto do arranjo quanto da configuração na paisagem. Assim sendo, a estrutura sígnica da imagem não é ignorada pela abstração teórica sobre a paisagem, do mesmo modo como a epistemologia não desautoriza uma ontologia. Mas, para que isso ocorra, é preciso que antes haja um retorno à paisagem.

Desse modo, a ação do pensamento é o "segundo momento" ${ }^{\circ}$ que se desdobra na paisagem, e o arranjo espacial é circunscrito na medida em que as práticas espaciais nele se inserem. Com isso, poder-se-ia falar em geograficidade. É pelas práticas espaciais que a própria

6 Faz-se referência aos momentos da abstração pensados por Silva (2000). $\bigcirc$ movimento paisagem-lugar-paisagem expressa melhor a propositura do autor, para quem o "espaço vivido" é uma mediação, e não ponto de chegada, situada na abstração ante a racionalidade. Na abstração, o significado empírico é ultrapassado, porque em si-mesmo não guarda em seu interior um significado teórico, ao menos que seja pela intuição. $\bigcirc$ "espaço vivido" tem sua origem na aparência, na contemplação da "paisagem". Assim, abstrai-se o nada, num primeiro momento, projetando-se ao real amparado pela objetividade que, já nesse instante, se fixa na aparência por uma de suas dimensões: a imagem abstrata. Num segundo momento, o olhar teórico da Geografia, por meio da razão e do método, lança-se novamente na abstração, que já conforma outro momento. Neste último, a abstração não é mais a mesma, pois é acompanhada pelo raciocínio e por uma ideia concreta. Nesse ponto, a condição estática do pensamento concreto é posta em questão, dirimindo-se no movimento promovido pela contradição entre ideias abstrata e concreta. Dessa maneira, a experiência como outra dimensão da objetividade compartilha espaço com a dimensão da interiorização supra-sensível sustentada pela elitrição. 
percepção da paisagem, numa multiescalaridade, a transformam em práticas geográficas. $\bigcirc$ movimento do singular ao universal é a própria constituição da falação do que se observa e experimenta. Mas a paisagem é, desde o início, uma forma de linguagem, porque é texto e intertexto, ao mesmo tempo (Moreira, 1997). Isto é, uma maneira de expressar o mundo e organizá-lo. Os "instantes" da conformação ontológica lançados pelos imediato e mediato encorajam uma leitura de um mundo plural e capaz de lançar olhares à simbiose do real e a sua representação sígnica.

No mediato, o real já é abstraído pela ciência geográfica que, pela fala, conforma o projeto científico que a representação pelo espaço vivido não consegue alcançar. É preciso ultrapassar o espaço vivido para clarear o projeto da Geografia e das geografias, esboroando os limites do real-aparente. Ontologicamente, o arranjo parte da necessidade em direção à liberdade, uma tarefa que se perpetua por localização-distribuição produzido pelo homem, agora ser social, que transforma a relação sociedade-natureza em sociedade-espaço a partir do impulso sob a produção dos mecanismos de existência ansiando sua reprodução. $\bigcirc$ espaço, então, é uma abstratividade que antecede tudo isso. Isto é, ele não é tido como representação advinda de uma abstração concreta da "coisa" extensa, isotrópica. Isso porque a mediaticidade do espaço consubstanciada no imediato esteia-se na vinculação das relações projetadas na concreticidade, isto é, pelo concreto que já é "algo" abstrato. A paisagem prontamente se estabelece no e como real, e não mais como um aparecimento ou acontecimento dele mesmo (Moreira, 2012a).

Por isso, Moreira afirma ser a imagem o encontro entre o de dentro e o de fora, admitindo uma alternativa à dualidade razão-símbolo. Em suas palavras:

[... ] o campo privilegiado da fusão é a imagem - o fruto do corpo enquanto o espaço do fora-dentro verdadeiro -, a qual, vista como relação de fora, é objeto e, como relação de dentro, é signo. Objeto e signo nela se encontram numa unidade de apreensão racional e simbólica ao mesmo tempo (Moreira, 2012a, p. 95).

Da mesma forma como Silva (2000) pretendeu romper com a dualidade real-imaginário imposta pelo materialismo clássico, Moreira (2012a, p. 95) também o fez, buscando abarcar os primados ontológicos do homem ou, em suas palavras, "a totalidade da condição humana". É na imagem que se combinam as relações de fora e de dentro. Há uma dissociação entre partes indissociáveis, entre objeto e signo. A dialética presente nessa combinação desperta ao homem uma corporeidade integralizada, e não mais dicotômica. É, no entanto, uma tarefa difícil, daí a urgência de se pensar a percepção para além dela mesma.

Moreira (2007) insiste na importância da práxis na maturação da condição ontológica do homem. Pela ambientalização, a paisagem estática dá lugar a uma paisagem movente, dinâmica, que recolhe a polissemia de olhares distantes de uma contemplação pura. Mas não é uma atividade presa ao "sentir-se no mundo", como se a geograficidade fosse uma categoria-suporte e pré-concebida da existência (uma ideia presente na filosofia do neuropsiquiatra Erwin Straus, como veremos adiante). É, em verdade, uma circunscrição do ser-com-os-outros, por isso, concebida na diversidade. 
O diverso encontra-se na contrariedade, de modo que a unidade espacial é justamente aquela que une os contrários. Na tradição do pensamento geográfico, a identidade une as diferenças veladas, pela homogeneização e pelo afastamento do olhar voltado para as práticas espaciais (Moreira, 2007). Aqui, então, a unidade espacial recolhe os contrários pela identidade. Do mesmo modo como a diferença ontológica anunciada na Filosofia afirmou que ser e ente não são o mesmo, mas que, na mesmidade, se revelam pela co-pertinência (Heidegger, 2009), a diferença geográfica espacializa a própria diferença pela diferenciação e pela heterogeneidade, mas sempre permeada pela interação (Moreira, 1999).

Desse modo, a diversidade ou a diferença (des)cobre um horizonte espacial. Na interação, a experimentação do diverso estreita os laços íntimos entre o homem e o mundo. Neste processo, o sistema de significações é decodificado pelo homem. Tornado isso uma irrelevância ou uma ação confusa, o homem adentra a duplicidade, na formatação de uma obstacularização no cerne da relação entre a razão e o simbólico, ou os espaços de fora e o de dentro. E diríamos, também, que a confusão entre o espaço, a espacialidade e a espacidade se presentificaria. ${ }^{7}$

Straus (1936), pelo olhar da psicologia fenomenológica, escreve que a percepção diz respeito à geografia, de modo que se percebe sempre um algo fixo num espaço objetivo e universal. A objetividade e a universalidade, juntas, não abarcam aquilo que se conhece apenas no sentir - que é a paisagem - porque, além de ela estar fora de qualquer possibilidade científica, a paisagem não é cartografável. Esse mapeamento está muito próximo àquele proferido por Lacoste (1988), quando entende que a carta é sempre uma representação do real, como se o real só fosse isso quando cartografado. É real aquilo que pode e deve ser cartografado. $\bigcirc$ geográfico, então, advém da abstratividade intelectiva que ganha forma nos mapas. Por isso, o espaço geográfico confunde-se com o espaço da percepção.

Diferente disso, a paisagem não é categoria geográfica, nem manifestação geográfica, porque é sentida ainda que imaterialmente. Ela é resultado de uma ambiência, a partir de uma alienação do corpo no espaço do sentir, a mesma que não pressupõe uma ambientalização. Moreira assegura o oposto. É como se o espaço de fora fosse uma categoria distante e extensa e o de dentro fosse o resultado da ideação pelo espaço geográfico, e não pela paisagem, porque dela não se retira qualquer objetividade (sempre atrelada à cartografia). É importante salientar, nesta concepção, que a situação desautoriza a possibilidade de se pensar ou, melhor, sentir a paisagem. Para Straus, a paisagem é um acontecimento pré-cultural e imediato, já para Dardel (2011), é uma mediação. Não seria isso a relação homem-meio pensada por Martins (2007)?8 Posto como o universo da interação, por onde a escolha do homem capta as possibilidades do mundo, o meio é a própria mediação. Pelo ato gnosiológico, o homem prolonga a sua geograficidade, pois, "esse 'objeto' que possui geograficidade emerge da coexistência e da alteridade do homem em relação ao meio, da sociedade ante a natureza” (Martins, 2007, p. 39). A paisagem, aqui, ultrapassa a imediaticidade.

7 Moreira (2012b, p. 81) diferencia esses termos da seguinte forma: "a espacidade indica o estado histórico do conceito [geográfico]; o espaço o seu fundo ontológico; e a espacialidade, o seu modo ôntico". Quando não bem identificado e esclarecido, o geográfico recai na incapacidade de pensar a geograficidade, porque o metabolismo homem-espaço não se reverbera.

8 Sobre o tema em questão, ver Martins (2007). 


\section{Considerações finais}

É pela ambientalização que o homem externaliza sua geograficidade, mas sempre partindo da práxis, porque, do contrário, a paisagem se estabeleceria numa dimensão não ontológica, como em Straus (1936). E trata-se da paisagem cujo significado não se respalda na contemplação, na admiração ou no olhar, mas no geográfico. A paisagem se torna geográfica quando o espaço lhe oferece o "fundo real ou imaginário" (Dardel, 2011, p. 31), admitindo-se a mediaticidade e a pré-ocupação com a reflexão sobre aquilo que se move e se transforma, e não sobre uma fixação.

Moreira (2004, p. 32) também atribui ao espaço a responsabilidade de, junto com o real concreto do território, tornar a paisagem o núcleo do ponto onde ocorre a "convergência das ontologias". Cremos que seja esse o ponto de partida: conceber a paisagem como o possível caminho de investigação ontológica sobre a constituição do geográfico. Pensar a paisagem é vê-la no movimento da concretude, pelas diferentes escalas qualitativas (gerais e particulares). É esse o percurso de ultrapassagem da simples localização e abstração do fenômeno que, circundado por esse processo, se torna a contraparte do algo concreto e distante da ideia concreta.

\section{Referências}

BARBOSA, J. L. O ordenamento territorial urbano na era da acumulação globalizada. In: SANTOS, M. et al. Território, territórios: ensaios sobre o ordenamento territorial. 3a ed. Rio de Janeiro: Lamparina, 2011.

BERNARDES, A. H. Das perspectivas ontológicas à natureza do internauta: contribuição à epistemologia em Geografia. Tese (Doutorado em Geografia) - Faculdade de Ciências e Tecnologia, Universidade Estadual Paulista, Presidente Prudente, 2012.

DARDEL, E. O homem e a terra: natureza da realidade geográfica. São Paulo: Perspectiva, 2011.

HARVEY, D. Condição pós-moderna: uma pesquisa sobre as origens da mudança cultural. 21 la ed. São Paulo: Loyola, 2011.

HEIDEGGER, M. Ser e tempo. 4a ed. Petrópolis, RJ: Vozes, 2009.

LACOSTE, Y. A Geografia: isso serve, em primeiro lugar, para fazer a guerra. São Paulo: Papirus, 1988.

OS PENSADORES. Bergson: cartas, conferências e outros escritos. Seleção de textos e trad. Franklin Leopoldo e Silva. São Paulo: Nova Cultural, 1989.

OS PENSADORES. Heidegger: conferências e escritos filosóficos. Trad. e notas Ernildo Stein. São Paulo: Abril Cultural, 1973.

MARTINS, E. R. Geografia e ontologia: o fundamento geográfico do ser. Geousp - Espaço e Tempo, n. 21, p. 33-51, 2007. 
MOREIRA, R. O racional e o simbólico: o de fora e o de dentro na Geografia. In: MOREIRA, R. Geografia e práxis: a presença do espaço na teoria e na prática geográficas. São Paulo: Contexto, 2012a. p. 95-101.

MOREIRA, R. Da espacidade à espacialidade: os contrapontos de uma teoria geral em Geografia. In: MOREIRA, R. Geografia e práxis: a presença do espaço na teoria e na prática geográficas. São Paulo: Contexto, 2012b. p. 81-94.

MOREIRA, R. Conceitos, categorias e princípios lógicos para o método e o ensino da Geografia. In: MOREIRA, R. Pensar e ser em Geografia: ensaios de história, epistemologia e ontologia do espaço. São Paulo: Contexto, 2010. p. 105-118.

MOREIRA, R. Da região à rede e ao lugar: a nova realidade e o novo olhar geográfico sobre o mundo. Etc..., espaço, tempo e crítica, v. 1, n. 1(3), p. 55-70, 2007.

MOREIRA, R. Marxismo e geografia: a geograficidade e o diálogo das ontologias. GEOgraphia, v. 6, n. 11, p. 21-37, 2004.

MOREIRA, R. A diferença e a geografia: 0 ardil da identidade e a representação da diferença na geografia. GEOgraphia, v. 1, n. 1, p. 41-58, 1999.

MOREIRA, R. A pós-modernidade e o mundo globalizado do trabalho. Revista Paranaense de Geografia, v. 1, n. 2, p. 48-56, 1997.

SANTAELLA, L. O que é semiótica?. 3a ed. São Paulo: Brasiliense, 1985.

SANTOS, M. A natureza do espaço: técnica e tempo, razão e emoção. 4a ed. São Paulo: Edusp, 2006.

SANTOS, M. Metamorfoses do espaço habitado: fundamentos teórico e metodológico da Geografia. São Paulo: Hucitec, 1988.

SILVA, A. C. A aparência, o ser e a forma: geografia e método. GEOgraphia, v. 2, n. 3, p. $7-25,2000$.

STRAUS, E. W. Le mouvement vécu. Recherches philosophiques, Paris, v. 5, p. 112-138, 1936. 